\title{
Anemia prevalence and its associated risk factors among Minangkabau pregnant women in West Sumatra, Indonesia: findings from VDPM cohort study
}

\author{
A.S. Aji ${ }^{1,2}$, Y. Yusrawati ${ }^{3}$, S.G. Malik ${ }^{4}$ and N.I. Lipoeto ${ }^{5}$ \\ ${ }^{1}$ Department of Nutrition, Faculty of Health Sciences, University of Alma Ata, Yogyakarta 55183, Indonesia, \\ ${ }^{2}$ Biomedical Science Department, Faculty of Medicine, Andalas University, Padang 25172, West Sumatra, Indonesia, \\ ${ }^{3}$ Department of Obstetrics and Gynaecology, Faculty of Medicine, Andalas University, Padang 25172, West Sumatra, \\ Indonesia, \\ ${ }^{4}$ Eijkman Institute for Molecular Biology, Ministry of Research, Technology and Higher Education, Jakarta 10430, \\ Indonesia and \\ ${ }^{5}$ Faculty of Medicine, Andalas University, Padang 25172, West Sumatra, Indonesia
}

Anemia during pregnancy remain to be a public health problem in developing countries especially in tropical countries. In pregnancy, anemia can cause bleeding complications in the mother throughout the pregnancy period, in labor, and after the baby is born, as well as impaired growth in the fetus. ${ }^{1}$ The aim of this study was to assess the prevalence and its associated risk factors of anemia among Minangkabau pregnant women in West Sumatra, Indonesia.

This was a secondary data analysis from "Vitamin D Pregnant Mother (VDPM) study in West Sumatra".,3 The third trimester pregnant women were enrolled from the public health centers in West Sumatra Province from January to March 2018. Structured questionnaires were used to collect the data of demographic, socio-economic, anthropometry, and health history. A binary logistic regression was created to assess the risk factors of anemia. In all cases, $P$ value less than 0.05 was considered statistically significant. Based on WHO criteria, anemia status was defined based on the hemoglobin $(\mathrm{Hb})$ concentration less than $11.00 \mathrm{~g} / \mathrm{dl} \mathrm{during}$ pregnancy and the categorization is performed using $\mathrm{Hb}$ levels. ${ }^{4} \mathrm{Hb}$ concentration was determined from capillary blood from a finger-pricked (EasyTouch ${ }^{\circledR}$ GCHB) by healthcare workers in the public health centers where all subjects did their antenatal visits in the third trimester.

In total, 176 pregnant women enrolled in this study. The prevalence of anemia was $109(61.90 \%)$ and $114(64.80 \%)$ were not taking an iron supplement during pregnancy. The mean of hemoglobin concentration was $10.56 \pm 1.41 \mathrm{~g} / \mathrm{dL}$. Moderate and mild anemia prevalence were $34 \%$ and $27 \%$, respectively. The third trimester of pregnant women anemia status was associated with women who had less minimum wage per month (Adjusted Odd Ratio (AOR): 5.15; 95\%CI: 1.30-20.47), low-moderate maternal nutrition knowledge (Adjusted Odd Ratio (AOR): 15.88; 95\%CI: 3.82-66.02), pre-pregnancy BMI <25 kg/m² (Adjusted Odd Ratio (AOR): 11.82; 95\%CI: 2.70-51.69), and no adherence iron supplement intake status (Adjusted Odd Ratio (AOR): 29.69; 95\%CI: 6.58-133.91).

We found a high prevalence of anemia status in the third trimester of pregnant women in West Sumatra. Therefore, raise awareness of iron supplementation and met nutrition requirement during pregnancy need to be considered to improve maternal health status to reduce anemia. However, further studies required with large sample size to confirm these findings.

1. A. Imdad et al. (2012), Paediatric and Perinatal Epidemiology 26, 168-177.

2. Aji, A.S. (2019). BMC Pregnancy Childbirth 19, 183.

3. Aji, A.S. (2020). J Diabetes Metab Disord 19, 91-103.

4. WHO. (2011). WHO/NMH/NHD/MNM/11.1, Geneva: WHO. 